BULGARIAN ACADEMY OF SCIENCES

CYBERNETICS AND INFORMATION TECHNOLOGIES • Volume 15, No 5

Special Issue on Control in Transportation Systems

Sofia $\bullet 2015$

Print ISSN: 1311-9702; Online ISSN: 1314-4081

DOI: $10.1515 /$ cait-2015-0021

\title{
Smart Travel Planner for Urban Sustainability
}

\section{Jacek Malasek}

Road and Bridge Research Institute, Warsaw, Poland

Email: jmalasek@ibdim.edu.pl

Abstract: The Smart Travel Planner concept for an optimal travel choice, supported by a Personalized Internet Portal, has to promote the sustainable urban mobility. STP is an important tool for Sustainable Urban Transport Decalogue's implementation that is intended to result in lower emissions, better health and lower investment costs in the road infrastructure. The questionnaires included are for checking its public acceptance in the city and at end users' level.

Keywords: Smart travel planner, sustainable urban transport, public acceptance.

"The European Innovation Partnership for Smart Cities and Communities is about making investments in sustainable development in as many cities as possible. Creating equal partnership between cities and companies based on synergies between ICT, energy and mobility will lead to projects that make a real difference in our everyday lives."

Gunter H. Oettinger, EU Commissioner for Energy, November 2013

\section{Smart travel choice in a smart city}

The core idea of Smart Cities is to better connect the human capital, social capital and ICT infrastructures in order to generate greater and more sustainable economic development and better quality of life for citizens. The concept of Smart Cities calls for intelligent approaches to local economy, mobility and environment by focusing on people's needs and interests. In the long-term, every city should provide 
improved and smarter public services that are more citizen-centred, economically viable and environmentally sustainable. There is a need for a flexible partnership between the public and private sectors, as well as diverse industries, such as telecommunication, energy providers, manufacturers and suppliers to ensure improvements in mobility, energy consumption, governance and social cohesion in European cities [1]. At present the modal split of the transport in Europe is dominated by passengers' cars accounting for $73.4 \%$ of passenger traffic compared to just $1.4 \%$ for tram and metro combined. According to the World Health Organization, some 40 million people in the 115 largest cities in the EU are exposed to air exceeding WHO air quality guideline values for at least one pollutant [2].

The biggest challenge of sustainable transport policy in urban areas is to decrease the car use in densely populated areas where the highest traffic flows are observed. Although the idea of sustainability is well known since 80 -ies, it will be useful for this paper to explain how it is understood here. The implementation of sustainable development for a smart city is to support the economic growth with minimal harm for the environment and high living standards. In case of sustainable transport this means less energy and land consuming investments - sustainable use of the environment looks for profits not at present but in a long-term perspective.

In most of the Western European countries it is entirely understood that today's investments in the physical environment, in particular in the infrastructure and mobility, are the main driver for urban economic and environmental vitality of tomorrow. Achieving a smart green and integrated transport system is a key to sustaining and developing the economic and social vitality of urban Europe. Within this context the challenge is to deliver the next generation of infrastructure governance, design, management and operation. This enables optimal accessibility, liveability, health, safety and security across the scales from the local daily urban system to the wide EU-regions that cluster metropolitan areas [3]. However, the new member states are also working on modern urban transport policies, e.g. Romania for the first time starts to develop sustainable mobility plans, carrying out a consultancy intended to implement these plans and public service obligations on public transport and other environmental friendly travel modes [4].

As mobility is one of the important living standards and it is a big achievement of our civilization, we have to be sure that any restrictions for the car use will not decrease an indispensable mobility. Keeping only indispensable mobility in mind means that the policy measures should try to reduce the need for car usage by other solutions: better communication, attractive public transport, modern land use, and last but not least clever and sound transportation policy.

Good use of better communication can substitute a lot of travels. Internet and other telecommunication services can substitute: personal meetings (you can call, fax or send e-mail), everyday work trips by tele-work (working at home), business trips (visiting a bank, city administration, etc.) and looking for goods in shops. Attractive public transport means: quick travel by preferences in traffic (separated right-of-way for trams, bus lanes, priority at junctions, etc.); cheap (subsidized) tickets; short, convenient and safe walking distance to mass transit stops; short waiting time at the Public Transport (PT) stops (smaller vehicles where needed), or 
reliable time tables and well organized interchanges; call-and-ride services mostly for handicapped.

Land-use planning in urban areas should follow such rules as: work close to home (because of big achievements in making industry clean there is no need to separate the workplaces according to the Athen's Charter) and shops close to home (hypermarkets generate high volumes of car traffic). In general: the Multifunctional and Intensive Land Use (MILU) should be promoted. Main trip generators (highrise office buildings, shopping malls, sport arenas, etc.) should be located close to the main PT corridors and multimodal terminals. Urban sprawl should be stopped (low density generates additional car traffic) using financial and administrative measures.

Coordination of spatial and transport planning policy [5] means: balance in the CBD of three capacities: internal road network $=$ external access roads $=$ internal parking lots; parking zones (standards for maximum parking spaces per 1000 sq. m of offices in CBD and minimum in the outskirts with law density); $\mathrm{P}+\mathrm{R}$ system close to the PT terminals outside the downtown area; bicycle routes network development and well facilitated pedestrian areas. Transport Infrastructure Integrated with Land-Use Planning (TIILUP) is a research programme initiated by the Dutch Rijkswatestaat, under the umbrella of the Forever Open Road programme [6].

\section{Sustainable urban transport policy}

The measures above mentioned do not include enforcement like parking and road pricing, limited access to specified areas, etc. Enforcement can help policy implementation and usually it is quite efficient, but a more elegant solution is to attract people to other transport modes than to forbid the car use administratively. In the cities, the regions or even the countries facing really big transportation problems, the soft measures above mentioned must be supported by more painful administrative decisions. Ten measures or commandments, called the Decalogue for Sustainable Urban Transport Strategy [7], could be here very helpful:

1. Promotion of the public transport modes

2. Car restrictions within the cities

3. Fuel prices can never go down

4. Ecological transport tax

5. Promotion of more environmental friendly vehicles

6. Equal access to PT modes

7. Co-financing of the transport investments

8. Sustainable spatial planning policy

9. Better telecommunication services

10. Better goods transport management.

Obviously, the final decision on implementation of all measures above mentioned must be done during public participation process attended by all main groups of the city stakeholders. 
However, promoting the environmental friendly travel modes we should not forget the car drivers' needs and understand that in the near future the autonomic systems for personalized mobility services will serve also autonomous cars. Autonomously, the self-driving vehicles will affect transport planning decisions, such as road and parking supply, as well as public transport demands. The autonomous vehicles within a decade or two will probably enable doubling of the highway capacity, but may be restricted only to special, non-general-purpose traffic lanes. In 2040-ies the autonomous vehicles are likely to represent approximately $50 \%$ of the new vehicle sales, $30 \%$ of the total vehicle fleet and $40 \%$ of the total vehicle travel [8]. Even now the basic cars have 30 or more computers (some luxury cars more than hundred - the electronics represent $15-20 \%$ of their cost) and we have to make a good use of it for improving the city environment [9].

At present the major car producers are working on their models of smart and connected cars while the US Department Of Transport (USDOT) wants to make them mandatory by 2017, since all are convinced of the benefits and potentially big impact they will have on safety, mobility and the environment - the test results show a range of fuel reduction between 4.5 and $25.1 \%$ in cars and $2.4-15.3 \%$ for trucks [10]. Another USDOT program - Real-Time Information Synthesis (AERIS) shows that the application itself can provide average fuel savings of 5-10\% per vehicle, what makes annual savings of 170 USD for cars and 280 USD for SUVs, based on vehicles driving 8000 miles per year on arterial roads [11]. Big energy savings can be done also by using the smart street lighting. Solid-state lighting solutions offer significant energy savings over HPS by both eliminating the light spill and delivering more efficient and uniform lighting with lower overall lumen output. In Edmonton (Canada) the streetlights account for $21 \%$ of the city power consumption and now they are trying to reduce this by 40 to $50 \%$ [12].

\section{Smart travel planner}

Smart Travel Planner (STP) and its database could be used for implementing sustainable urban transport policy in more efficient way. The real novelty of our STP proposal is: it will work on a strictly personalized Internet portal, will cover environmental aspects (pollution counting), the participants will be awarded and the business model for cities implementing STP makes it more economically viable. STP will provide reliable advising for optimal travel planning, according to: actual traffic conditions, road accidents, road works, PT problems in operation and air pollution observed - taking into account also the personal circumstances. The results of TrafficCheck.at (the project funded by the Austrian ministry responsible for traffic, innovation and technology) will be followed here. With their smartphones, TrafficCheck contributors can track their positions on OpenStreetMap while underway and select the signal-controlled intersections they wish to rate. They enter their transport mode to provide information on whether the rating comes from the perspective of a car driver, cyclist, pedestrian or public transport passenger. The crowd sourcing contributors will then report problems or enter the score, rating from 1 star for an intersection regarded as bad up to 4 stars for one 
regarded as satisfactory. The score is based on factors, such as waiting time, visibility, conflicts between road users and system layout [13].

Personal needs, habits and limitations should be uploaded by each system participant to the Personalized Internet Portal (PIP) which will cover the following data: home and workplace locations; working hours; other obligatory trips (taking children to school, sport activities, church, etc.); PT season ticket (if any); using own bicycle or a city bike; accepted cycling and walking distance (depending on the weather conditions); car type (for calculation emissions - or e-car); location of favourable P+R; membership of a carpool team or a car-sharing system; accepted travel time limit and accepted travel cost.

If something unusual happens (having to take a car because of a heavy luggage, etc.) PIP should be informed before. Before each travel (obligatory during pick-hours from home and work) suggestions on the most suitable travel mode, with detail route description (in case of PT - what time at what bus stop, where a change for a metro; also best route for cycling and walking) is available on one's PIP or a smart phone or navigation system. Those choosing a car will get for their on-board navigation an optimal route, according to the actual traffic constraints and air pollution in a particular area. Using an e-car or a car instrumented for eco-driving, and following the suggested guidance will be awarded.

In each city, several stakeholders must be involved in STP implementation for fulfilling the following tasks:

- Individuals: To inform PIP on travel needs and try to follow the social behaviour principles.

- Big companies (workplace providers): to promote tele-working, decrease capacity of parking lots, participants in PT season tickets cost, provide cycling infrastructure (a shower, etc.).

- PT Authority: to improve the quality of operations, adjust the capacity to a demand and inform the Traffic Management Centre on-line on PT vehicles location.

- Traffic Control Centre: Avoiding traffic jams (alternative routes), informing on-line of the traffic constraints, parking capacity and sector traffic speed.

- Environmental Dpt.: to inform on-line about air pollution in particular areas.

- STP operator within Traffic Management Centre: to gather and proceed data, advice individuals, coordinate PT and road traffic.

- Media: to promote the idea of sustainable transport using celebrities and individuals with their success stories.

- City Hall: to implement sustainable transport policy measures (including MILU) and calculate gains of changing drivers behaviour.

The Business Model idea for STP implementation looks like that. Financial Div. of the City Transport Dpt. calculates the gains of the lower car use, taking into account: lower costs of the road construction and maintenance, new work places, shorter travel times, better city environment, better inhabitants health and a Green City image - minus costs of STP implementation. We believe there will be some profits which must be used for: further improving of the environmental friendly 
travel modes ( $\mathrm{PT}, \mathrm{P}+\mathrm{R}$, cycling, etc.); tax relief for participating companies and, what's crucial, for the incentives of individuals (everyone gathers points for each eco-friendly choice): free PT season tickets, access to the "rare goods": best kindergarten, a star concert free ticket, etc.

The rules of competition for individuals (STP users) are a part of the city Business Model:

- Each travel mode decision is calculated in PIP - comparing with using the average (for the city) car emissions during the pick-hour.

- Social cost (covers: emission, noise, other travellers' time losses, risk of traffic accidents) of each travel is measured in Euro and changed on points.

- When using a car with higher emissions one receives minus points, when travel by e-car, a new car, on alternative fuels, etc., is awarded by plus points. A higher number of plus points you will receive choosing PT modes, cycling or walking.

- Those with the highest points' number are periodically awarded and presented by the media.

Quite complicated and comprehensive STP systems (as presented above for the year 2030) will cost more, but their efficiency in changing drivers' behaviour, decreasing pollution and improving traffic conditions will be higher. Each city has to decide what quality of TMC, PIP and STP to choose - according to its budget surplus and expected gains. Cost/Benefit analysis should be here applied.

\section{Will it work?}

The main goal of the ARTS EU research project entitled "ARTS for Improving Efficiency, Ecology and Traffic Safety" is to unite and align groups from transport studies, computer science, engineering, as well as professionals into a world leading research community that will develop radically new ways of designing road transportation support systems based on the ideas of autonomic systems.

One of the project's secondary objectives is to create a Business Model for the city wanting to implement a Smart Travel Planner, for further development of sustainable urban transport policy, changing the drivers' behaviour and improving the city environment.

For checking local governments and end-users interest in developing and using ARTS applications (e.g., STM), two questionnaires are prepared.

4.1. ARTS questionnaire for the City (City Hall departments for roads, environment, finance and for the Public Transport Authority)

Are you interested in cooperation with the ARTS project? - YES or NO.

Are you interested in being a pilot city for the STP implementation? - YES or NO.

If the answer to one of these questions is YES, please be so kind and fill-in the questionnaire below, that will help us to orient on the city problems, on the chance 
of successful implementation of the Business Model and on the possibility of BM idea further improvements.

\section{Questions concerning the city}

1. Area (sq. km)

2. Population

3. Average salary

4. Unemployment rate $(\%)$

5. People tele-working (\%)

6. Modal split within its 10 years trends

7. Car ownership index (personal cars per 1000 inhabits)

8. What is the percentage of hybrid and e-cars?

9. Do carpool or car-sharing services exist?

10. Do call-a-ride services exist?

11. Environmental data on emissions $\left(\mathrm{CO}, \mathrm{CO}_{2}, \mathrm{NO}_{x}, \mathrm{NO}_{2}, \mathrm{PM}-10, \mathrm{SO}_{2}\right)$

12. Noise level data

13. Does the sustainable urban transport policy/strategy document exist?

\section{On public transport (PT)}

1. What is the PT management structure?

2. Routes (streets with bus, tram,..., services) length

3. Fleet numbers

4. Travel speed data

5. Single ticket price

6. 1 month network ticket price

7. What kind of preferences in the traffic for PT modes are used?

8. Location (on the PT routes network) and P+R lots capacity

9. Investment in a PT system during the last 10 years $(€)$

\section{On roads}

1. Road system characteristics (maps with road categories, pedestrian areas, traffic flows in p.c.u. during the pick hour...)

2. Parking/road charging system (location, tariffs...)

3. Car speed data during the pick hour

4. What kind of traffic problems (and where) should be solved?

5. What kind of ITS services are used?

6. What are the Traffic Management Centre functions?

7. What kind of software (and for what) is used?

8. Bicycle routes network with $B+R$ facilities

9. Does a City Bike system exist?

10. Investment in the road system during the last 10 years $(€)$

\section{On Business Model}

1. Do any travel planner services (on a webpage, on PT stops, on-board PT vehicles, mobile services) exist?

2. Do big companies have mobility plans (any promotion of eco-friendly travel behaviour)?

3. What kind of the environmental monitoring system is in use? 
4. What sustainable transport policy goal (no traffic jams, preferences for PT modes, decreasing pollution, cycling increase...) is your priority?

5. Does the City Hall cooperate with the media and NGOs on changing drivers' behaviour promotion?

6. What kind of incentives for the STP users you are ready to offer?

7. Is the presented Business Model economically viable?

8. What changes would you suggest?

Please find below the next questionnaire dedicated for the STP users.

Please try to distribute it - our suggestion is: Using NGOs on sustainable growth or environmental issues you cooperate with.

These questionnaires will be analyzed in the age groups 18-25, 30-65 (equally distributed by sex) and compared with the naturalistic driving survey results ongoing within EU research project UDRIVE (European Naturalistic Driving and Riding for Infrastructure and Vehicle Safety and Environment).

\subsection{ARTS questionnaire for STP users}

STP should provide reliable advising for optimal travel planning, according to actual traffic conditions, road accidents, road works, PT strikes and any other problems and air pollution, taking into account also the personal circumstances.

Personal needs, habits and limitations should be uploaded by each system participant to the Personalized Internet Portal (PIP) which will cover the following data:

- Home and workplace locations

- Working hours

- Other obligatory trips (taking children to school, sport activities, church, etc.)

- PT season ticket, if any

- Using own bicycle or a city bike

- Accepted cycling and walking distance, depending on weather conditions

- Car type (for calculation emissions - or e-car)

- Location of favourable P+R

- Member of a carpool team?

- User of car-sharing system?

- Accepted travel time limit

- Accepted travel cost (for taxi or call-a-ride service)

If something unusual happens (having to take a car because of a heavy luggage, etc.) PIP should be informed before.

Before each travel (obligatory during pick-hours from home and work) suggestions on the most suitable travel mode, with detail route description (in case of PT - what time at what bus stop, where a change for a metro; also the best route 
for cycling and walking) is available on one's PIP or a smart phone or navigation system.

Those choosing a car will get for their on-board navigation an optimal route, according to actual traffic constraints and air pollution in particular area. Using an e-car or a car instrumented for eco-driving, and following the suggested guidance will be awarded. Incentives for STP users (everyone gathers points for each ecofriendly choice) could cover free PT season tickets, access to the "rare goods": best kindergarten, star concert free ticket, etc. NO.

Are you interested in improving the traffic conditions in your city? - YES or

Are you interested in being the Smart Travel Planner user? - YES or NO.

If the answer to one of these questions is YES, please be so kind and fill-in the questionnaire below, that will help us to orient our self on your preferences and on the possibility of STP idea further improvements.

\section{Personal data}

1. Sex

2. Age

3. Education level

4. Are you a pupil, student, employed, self-employed, retired?

5 . What is your average salary?

6. Are you a car/motorcycle owner?

On your travel habits

1. Do you use a car?

2. What kind of a car you use (petrol/diesel HP/engine capacity cub. cm, hybrid, e-car)?

3. Are you a member of a carpool team?

4. Do you use car-sharing services?

5. What is your annual car millage (or in $\mathrm{km}$ )?

6 . How often you use a taxi in a month?

7. Do you use a bicycle and how often in a week?

8. What is your acceptable walking distance within the city?

9. What travel mode you use for obligatory trips (to school, workplace) within the city?

10. Do you use a season public transport ticket?

11. What is the distance from home to school/work?

12. How much time consuming is it (one way in $\mathrm{min}$ )?

13. Do you use a travel planner services?

14. Do you have a smart phone?

15. How much money could you safe in a month not using a car within the city?

16. Are you interested in environmental issues? 


\section{Your opinion on traffic problems in your city}

1. Are traffic jams a big problem?

2. What in your opinion should be done to solve this problem?

3. Any problems with the public transport services (too expensive, low frequency, poor travel comfort, poor accessibility, low speed...)?

4. What should be done to use public transport more often?

5. Any problems with bicycle infrastructure (no bicycle routes, no parking facilities, pilferage, no shower at the workplace)?

6. Do you feel safe when cycling within the city?

7. What should be done if you wish to use a bicycle in purpose trips more often?

8. Do you like walking?

9. Any problems with pedestrian infrastructure (sidewalks are too narrow, aesthetic/uninteresting design, long red lights, a lot of under/overpasses, drivers' attitude to pedestrians)?

\section{Concerning Smart Travel Planner}

1. Would you accept Personalized Internet Portal rules?

2. If not, on what conditions you could?

3. Would you need any incentives to be a Smart Travel Planner user?

4. What kind of incentives are you interested in?

5. What should be done to improve the Smart Travel Planner idea?

Thanks a lot for helping us in making our cities more people friendly.

Five respondents will be awarded by the Project team - we hope you will be one of them.

\section{Conclusion}

All readers are kindly asked to disseminate the questionnaire in their cities, helping in this way in checking the acceptance of our Smart Travel Planner idea. The smart urban transport system is what we need in Anthropocene - Age of Man [14], a new geologic epoch as Antonio Stoppani defined it by our massive impact on the planet. Remember: all that will remain after the Age of Man, despite of our wealthy societies, our megapolises and innovative technology will probably be only our $\mathrm{CO}_{2}$ footprint to be found in geological structures.

Acknowledgement: The paper is partially supported by FP7 Project 316087 ACOMIN "Advance Computing and Innovation".

References

1.@PublicPolicyEx, "Smart Cities, Smart Europe", April 2014. www.publicpolicyexchange.co.uk

2. MyWay, "Multi-Modal Journry Planning Made Easy to Encourage the Use of Sustainable Modes of Transport". www.myway-project.eu 
3. Ministry of the Infrastructure and the Environment of the Netherlands. Networking for Urban Vitality. Rijkswaterstaat, April 2014.

4. TRIP Newsletter March 2014. www.transport-research.info

5. Mala s e k, J. Greening Warsaw Transport System by Sustainable Urban Planning. - In: Conference Papers, Sustainable City, 2012 - 7th International Conference on Urban Regeneration and Sustainability, Ancona, 2012.

6. Ministry of the Infrastructure and the Environment of the Netherlands. Transport Infrastructure Integrated with Land-Use Planning. Rijkswaterstaat, December 2013.

7. M a l a s e k, J., A. J a ź d z i k-O s m ól s k a. Decalogue for Sustainable Urban Transport Strategy. - In: Conference Papers, Urban Transport, 2012 - 18th International Conference on Urban Transport and the Environment, A Coruna, 2012.

8. L it $\mathrm{m}$ a n, T. Ready or Waiting? Traffic Technology International, January 2014.

9. W i 11 i a m s, B. Proof of Ownership. - Thinking Highways, Vol. 9, 2014, No 1.

10. Casterman s, J. The Future is Green...eCoMove Green. - Thinking Highways, Vol. 9, 2014, No 1.

11. AERIS Program. Latest Results for AERIS Program Show Fuel Benefits. www.its.dot.gov/aeris/

12. B u 11 o u g h, J. D. Smart Illumination. Traffic Technology International, January 2014.

13. K o e s 1 i n g, S. Map 'n' tag. - Thinking Highways, Vol. 9, 2014, No 1.

14. K o l b e r t, E. Enter the Anthropocene - Age of Man. - National Geographic, 2011, No 12. 